\title{
Risk Factor Analysis for Predicting Kyphosis Reoccurrence of Thoracolumbar Burst Fracture Patients Treated with Posterior Short-Segment Fixation
}

\author{
Xiangyao Sun ( $\nabla$ sun.xiang.yao@163.com ) \\ Xuanwu Hospital Capital Medical University https://orcid.org/0000-0001-9385-2402 \\ Wenzhi Sun \\ Xuanwu Hospital \\ Hailiang Hu \\ Xuanwu Hospital
}

Wei Wang

Xuanwu Hospital

Tongtong Zhang

Xuanwu Hospital

Chao Kong

Xuanwu Hospital

Siyuan Sun

Purdue University

Yong Hai

Xuanwu Hospital

Shibao Lu

Xuanwu Hospital

Research article

Keywords: risk factors, kyphosis reoccurrence, posterior short-segment fixation, thoracolumbar burst fracture

Posted Date: May 24th, 2021

DOI: https://doi.org/10.21203/rs.2.14567/v4

License: (c) (1) This work is licensed under a Creative Commons Attribution 4.0 International License. Read Full License 


\section{Abstract}

Background: The thresholds of risk factors of kyphosis recurrence in thoracolumbar burst fracture patients were still controversial. The aim of this multi-center study was to identify these thresholds.

Methods: 169 patients were included in this study. Upper intervertebral angle (UIVA), lower intervertebral angle (LIVA), Cobb angle (CA), anterior vertebral height ratio (AVH\%), regional angle (RA), posterior vertebral height ratio ( $\mathrm{PVH} \%)$, vertebral wedge angle (VWA), anteroposterior ratio (A/P\%), Clinical assessment included Load Sharing Classification (LSC) score, Thoracolumbar Injury Classification and Severity (TLICS) score, Visual Analogue Scale (VAS), and Body mass index (BMI) were perioperatively evaluated. Patients were divided into KR group and none KR (NKR) group according to whether the loss of $\mathrm{CA}$ correction was less than $15^{\circ}$ or not. The risk factors of KR before or after implant removal were analyzed, respectively.

Result: There were significant improvements in postoperative parameters compared with preoperative parameters, such as AVH\%, A/P\%, VAS, CA, VWA, PVH\% $(P<0.001$, respectively), and UIVA $(P=0.02)$. Age $(A U C=0.828)$ and $B M I(A U C=0.846)$ were good predictors of $K R$ before implant removal. $B M I(A U C=$ 0.871 ) was a good predictor of $\mathrm{KR}$ after implant removal.

Conclusion: There were significant differences in risk factors of KR at different postoperative follow-up stages: age > 49 years, $\mathrm{BMI}>24$ were risk factors of $\mathrm{KR}$ before implant removal; $\mathrm{BMI}>25.17$ was a risk factor of $K R$.

\section{Introduction}

Thoracolumbar spine (T11-L2) is the most frequent site of vertebral fractures; the transition from the less mobile thoracic spine with support from the ribs and sternum to the more dynamic lumbar spine makes this junction a biomechanical weak point [1]. Therefore, most spinal injuries affect the thoracolumbar region, $17 \%$ of which are burst fractures [2].

The short-segment pedicle instrumentation with the screw insertion in the fractured vertebra (SSPI-f) usually provides sufficient fixation with good clinical outcomes [3]. However, it is also associated with common complications, such as failure of the instrumentation, the recurrence of kyphosis (KR) and sagittal spinal imbalance [4,5]. Jang et al. [6] reported that predictors of vertebra re-collapse for thoracolumbar burst fracture were age and the loss of preoperative body height. Nevertheless, they combined long-segment pedicle instrumentation with short-segment pedicle instrumentation in the study. Because the follow-up time of their study is only one year, they did not fully discuss the influence of implant removal on spinal correction. In addition, they failed to discuss the KR after SSPI-f, which seemed to be of greater clinical significance than vertebral body re-collapse. Chen et al. [3] studied the effect of implant removal on KR after implant removal on KR after SSPI-f, and found that the loss of correction was associated with anterior vertebra height ratio $(\mathrm{AVH} \%)<50 \%$, anteroposterior ratio and age. However, they did not fully analyze the factors influencing KR before implant removal. The thresholds of risk 
factors in their study were based on experience and the results of previous studies; however, these were not analyzed by receiver operating characteristic (ROC) curve. Therefore, their research methods need to be improved.

In order to solve all the problems mentioned above, we analyzed the risk factors of KR before implant removal and after implant removal respectively in the present study. To identify the thresholds of the risk factors, we used logistic regression model and ROC curve in the analysis. Cases gathered from three health centers were studied in this research, which would make the results more convincing.

\section{Materials And Methods \\ 2.1 Ethics statement}

Ethics Committee of the Xuanwu Hospital Capital Medical University approved this study. The approval number is Clinical study review [2018] 021. Written informed consent of each patient was obtained prior to the study.

\subsection{Inclusion and Exclusion Criteria}

We retrospectively reviewed 224 consecutive thoracolumbar burst fracture patients presenting to the hospitals (Xuanwu Hospital Capital Medical University; Beijing Chaoyang Hospital, Capital Medical University; Chui Yang Liu Hospital affiliated to Tsinghua University) between January 1, 2014 and January 1, 2016. All patients received SSPI-f within 3 days. The patients were older than 18 years. The follow-up time was two years. We removed the fixation device with about 12 months after SSPI-f. The inclusion criteria were as follows: Thoracolumbar Injury Classification and Severity (TLICS) score was more than 4 ; kyphosis was more than $15^{\circ}$; anterior vertebral height was less than $50 \%$. The exclusion criteria were as follows: Multiple contiguous fractures or non-contiguous fractures; bone mineral density (BMD) of the thoracolumbar spine was at least 2.5 SD below the mean of young normal men; pathological fracture such as tumor, ankylosing spondylitis, inflammatory arthritis; posterior fusion or posterolateral fusion, and laminectomy in the operation; neurological deficit, obsolete thoracolumbar fracture, previous history of spinal surgery. Finally, 169 (90 men and 79 women) patients were included in this study.

\subsection{Radiological Measurements}

Whole-spine X-ray (Philips Digital Diagnost) and computed tomography (CT) (Philips Medical Systems) were used to evaluate the patients. Superior endplate (SE) fracture in the fractured vertebra was evaluated on CT images. Radiographic parameters were obtained, preoperatively or postoperatively. In addition, the parameters were collected before implant removal and at last follow-up. The following radiological parameters $[3,6,7]$ were evaluated: Cobb angle $(C A)$ was measured between the inferior endplate (IE) of the lower adjacent vertebra (LAV) and the SE of the upper adjacent vertebra (UAV); vertebral wedge angle (VWA) was the angle between the IE and the SE of fractured vertebra; regional angle (RA) was defined as the angle between the IE of the UAV and the SE of the LAV; posterior vertebral 
height ratio $(\mathrm{PVH} \%)$ was calculated by the ratio of posterior height of the fractured vertebra $(\mathrm{PVH})$ to the average between posterior height of the UAV (PVH1) and posterior height of the LAV (PVH2); anterior vertebral height ratio (AVH\%) was calculated by the ratio of anterior height of the fractured vertebra (AVH0) to the average of anterior height of the UAV (AVH1) and anterior vertebral height of the LAV (AVH2); anteroposterior ratio (A/P\%) was the ratio of $\mathrm{AVHO}$ to $\mathrm{PVHO}$; upper intervertebral angle (UIVA) was the angle between the IE of UAV and the SE of fractured vertebra; lower intervertebral angle (LIVA) was the angle between the SE of LAV and the IE of fractured vertebra.

\subsection{Clinical Assessments}

The extent of anterior column comminution was assessed in accordance with Load Sharing Classification (LSC) score [8]. Back pain was evaluated according to a Visual Analogue Scale (VAS). Thoracolumbar Injury Classification and Severity (TLICS) score [9] was used to weight the severity of fracture. Body mass index (BMI) was used to evaluate the body size of the patients. Whether the patients got diabetes or not was also recorded in this research.

\subsection{Grouping Methods}

Patients with the CA less than $15^{\circ}$ were included in the KR group; however, patients with the CA more than $15^{\circ}$ were included in the none KR (NKR) group [10]. The risk factors of KR before or after implant removal were analyzed, respectively.

\subsection{Statistical Analysis}

SPSS 17.0 (SPSS Inc, Richmond, CA, USA) was used to perform the statistical analysis. Mean \pm standard deviations were used to represent continuous variables. Kolmogorov-Smirnov test was performed to the normal distribution of the data. Normally distributed values were analyzed with independent Student $t$ test. Skewed values were analyzed with Kruskal-Walllist test. Categorical variables were reported as the number of cases and were evaluated in Pearson's $\chi^{2}$ test. Candidate variables were identified for multivariate logistic regression model via univariate screening to identify the risk factors. ROC (receiver operating characteristic) curve was calculated by the results of multivariate logistic regression analysis. It was used to determine the predictability of the risk factors for KR. $P$ value $<0.05$ was considered of statistical significance.

\section{Results}

\subsection{Demographics}

The patients' mean age was $48.4 \pm 11.0$ years. In all of those patients, $6(3.6 \%)$ patients got diabetes mellitus. Superior endplate fracture occurred in $78(46.8 \%)$ patients. There were $6(3.6 \%)$ fractures in T11, 66 (39.3\%) in T12, 72 (42.8\%) in L1, $24(14.3 \%)$ in L2. The average preoperative BMI was $24.8 \pm 2.9$. In addition, preoperative TLICS was $6.5 \pm 1.0$, and LSC score was $5.9 \pm 1.1$. The mean follow-up time was $27.5 \pm 1.7$ months. 
There were significant improvements in postoperative parameters compared with preoperative parameters, such as VAS, CA, VWA, AVH\%, A/P\%, $P V H \%(P<0.001$, respectively), UIVA ( $P=0.02)$ (Fig. 1). However, no significant difference was found between preoperative LIVA and postoperative LIVA $(\mathrm{P}=$ $0.420)$.

\subsection{Risk factors of postoperative KR before implant removal}

The average correction loss before implant removal was $4.3 \pm 3.0^{\circ}$. Kyphosis reoccurred in 78 (46.4\%) patients. There were significant between-group differences among the number of females, age, BMI $(P<$ 0.001 , respectively), the number of cases with preoperative AVH\%, preoperative VAS, preoperative LSC ( $P$ $=0.001$, respectively), diabetes mellitus $(P=0.009)$, preoperative $\mathrm{PVH} \%(P=0.007)$, and preoperative $\mathrm{A} / \mathrm{P} \%(P=0.002)$ (Table 1$)$. 
Table 1

Comparison of preoperative parameters between KR Group and NKR Group

\begin{tabular}{|c|c|c|c|c|c|c|c|c|}
\hline \multirow{2}{*}{$\begin{array}{l}\text { Characteristic } \\
\text { Implant } \\
\text { removal }\end{array}$} & \multicolumn{2}{|c|}{ KR Group } & \multicolumn{2}{|c|}{ NKR Group } & \multicolumn{2}{|c|}{$t / \chi^{2}$ value } & \multicolumn{2}{|c|}{$P$ value } \\
\hline & Before & After & Before & After & Before & After & Before & After \\
\hline Female (n) & $\begin{array}{l}48 \\
(28.6 \%)\end{array}$ & $\begin{array}{l}72 \\
(42.9 \%)\end{array}$ & $\begin{array}{l}30 \\
(17.6 \%)\end{array}$ & $\begin{array}{l}6 \\
(3.6 \%)\end{array}$ & 13.365 & 39.908 & $\begin{array}{l}< \\
0.001\end{array}$ & $\dot{0} 001$ \\
\hline Age (year) & $\begin{array}{l}54.2 \pm \\
11.1\end{array}$ & $\begin{array}{l}52.1 \pm \\
10.3\end{array}$ & $\begin{array}{l}43.4 \pm \\
8.0\end{array}$ & $\begin{array}{l}40.8 \pm \\
8.1\end{array}$ & -7.164 & -7.089 & $\begin{array}{l}< \\
0.001\end{array}$ & $\begin{array}{l}< \\
0.001\end{array}$ \\
\hline BMI & $\begin{array}{l}26.6 \pm \\
2.5\end{array}$ & $\begin{array}{l}26.0 \pm \\
2.7\end{array}$ & $\begin{array}{l}23.3 \pm \\
2.3\end{array}$ & $\begin{array}{l}22.3 \pm \\
1.3\end{array}$ & -8.815 & -12.166 & $\begin{array}{l}<.001 \\
0.001\end{array}$ & $\begin{array}{l}<.001 \\
0.00\end{array}$ \\
\hline Diabetes (n) & $\begin{array}{l}6 \\
(3.6 \%)\end{array}$ & $\begin{array}{l}6 \\
(3.6 \%)\end{array}$ & $0(0 \%)$ & $0(0 \%)$ & 7.179 & 2.947 & 0.009 & 0.178 \\
\hline $\begin{array}{l}\text { Upper endplate } \\
\text { injury (n) }\end{array}$ & $\begin{array}{l}42 \\
(25 \%)\end{array}$ & $\begin{array}{l}60 \\
(35.7 \%)\end{array}$ & $\begin{array}{l}36 \\
(21.4 \%)\end{array}$ & $\begin{array}{l}18 \\
(10.7 \%)\end{array}$ & 3.221 & 5.487 & 0.88 & 0.021 \\
\hline $\begin{array}{l}\text { Preoperative } \\
\mathrm{CA}\left({ }^{\circ}\right)\end{array}$ & $\begin{array}{l}20.8 \pm \\
10.4\end{array}$ & $\begin{array}{l}19.6 \pm \\
9.1\end{array}$ & $\begin{array}{l}19.1 \pm \\
5.1\end{array}$ & $\begin{array}{l}20.5 \pm \\
4.9\end{array}$ & -1.346 & 0.828 & 0.181 & 0.409 \\
\hline $\begin{array}{l}\text { Preoperative } \\
\mathrm{RA}\left({ }^{\circ}\right)\end{array}$ & $\begin{array}{l}9.4 \pm \\
5.9\end{array}$ & $\begin{array}{l}8.9 \pm \\
5.6\end{array}$ & $\begin{array}{l}9.3 \pm \\
4.4\end{array}$ & $\begin{array}{l}10.2 \pm \\
3.8\end{array}$ & -0.155 & 166 & 0.877 & 0.110 \\
\hline $\begin{array}{l}\text { Preoperative } \\
\text { VWA }\left({ }^{\circ}\right)\end{array}$ & $\begin{array}{l}17.9 \pm \\
6.8\end{array}$ & $\begin{array}{l}17.6 \pm \\
6.2\end{array}$ & $\begin{array}{l}18.4 \pm \\
4.4\end{array}$ & $\begin{array}{l}19.3 \pm \\
4.1\end{array}$ & 128.009 & 2.112 & 0.573 & 0.036 \\
\hline $\begin{array}{l}\text { Preoperative } \\
\text { UIVA }\left(^{\circ}\right)\end{array}$ & $\begin{array}{l}-3.4 \pm \\
2.4\end{array}$ & $\begin{array}{l}-3.1 \pm \\
3.0\end{array}$ & $\begin{array}{l}-4.0 \pm \\
3.5\end{array}$ & $\begin{array}{l}-5.2 \pm \\
2.6\end{array}$ & -1.250 & -4.552 & 0.213 & $\begin{array}{l}< \\
0.001\end{array}$ \\
\hline $\begin{array}{l}\text { Preoperative } \\
\text { LIVA }\left(^{\circ}\right)\end{array}$ & $\begin{array}{l}-4.9 \pm \\
2.3\end{array}$ & $\begin{array}{l}-5.1 \pm \\
2.5\end{array}$ & $\begin{array}{l}-5.5 \pm \\
2.6\end{array}$ & $\begin{array}{l}-5.5 \pm \\
2.4\end{array}$ & -1.475 & -0.901 & 0.142 & 0.369 \\
\hline $\begin{array}{l}\text { Preoperative } \\
\text { AVH }\left(^{\circ}\right)\end{array}$ & $\begin{array}{l}55.6 \pm \\
11.8\end{array}$ & $\begin{array}{l}57.0 \pm \\
10.7\end{array}$ & $\begin{array}{l}63.0 \pm \\
10.9\end{array}$ & $\begin{array}{l}65.0 \pm \\
12.5\end{array}$ & 4.222 & 166 & $<.001$ & $\dot{0}_{0.001}$ \\
\hline $\begin{array}{l}\text { Preoperative } \\
\text { PVH\% }\left(^{\circ}\right)\end{array}$ & $\begin{array}{l}84.1 \pm \\
5.8\end{array}$ & $\begin{array}{l}84.6 \pm \\
5.2\end{array}$ & $\begin{array}{l}86.1 \pm \\
2.9\end{array}$ & $\begin{array}{l}86.2 \pm \\
2.7\end{array}$ & 2.745 & 2.607 & 0.007 & 0.010 \\
\hline $\begin{array}{l}\text { Preoperative } \\
\text { A/P\% }\left({ }^{\circ}\right)\end{array}$ & $\begin{array}{l}53.3 \pm \\
11.6\end{array}$ & $\begin{array}{l}54.4 \pm \\
10.3\end{array}$ & $\begin{array}{l}58.3 \pm \\
8.9\end{array}$ & $\begin{array}{l}59.4 \pm \\
10.2\end{array}$ & 3.118 & 2.994 & 0.002 & 0.003 \\
\hline $\begin{array}{l}\text { Preoperative } \\
\text { VAS }\end{array}$ & $\begin{array}{l}6.5 \pm \\
0.8\end{array}$ & $\begin{array}{l}6.4 \pm \\
0.7\end{array}$ & $\begin{array}{l}6.1 \pm \\
0.7\end{array}$ & $\begin{array}{l}6.0 \pm \\
0.8\end{array}$ & -3.259 & -2.688 & 0.001 & 0.008 \\
\hline $\begin{array}{l}\text { Preoperative } \\
\text { TLICS }\end{array}$ & $\begin{array}{l}6.5 \pm \\
0.6\end{array}$ & $\begin{array}{l}6.5 \pm \\
1.2\end{array}$ & $\begin{array}{l}6.5 \pm \\
1.3\end{array}$ & $\begin{array}{l}6.4 \pm \\
0.5\end{array}$ & 0.034 & -0.224 & 0.973 & 0.823 \\
\hline $\begin{array}{l}\text { Preoperative } \\
\text { LSC }\end{array}$ & $\begin{array}{l}6.2 \pm \\
1.0\end{array}$ & $\begin{array}{l}6.1 \pm \\
1.2\end{array}$ & $\begin{array}{l}5.7 \pm \\
1.2\end{array}$ & $\begin{array}{l}5.7 \pm \\
1.1\end{array}$ & -3.355 & -2.079 & 0.001 & 0.039 \\
\hline
\end{tabular}




\section{Characteristic}

KR Group

NKR Group

$t / \chi^{2}$ value

Pvalue

Notice: CA, Cobb angle; RA, regional angle; VWA, vertebral wedge angle; UIVA, upper intervertebral angle; LIVA, lower intervertebral angle; AVH\%, anterior vertebra height ratio; $\mathrm{PVH} \%$, posterior vertebra height ratio; $\mathrm{A} / \mathrm{P} \%$, anteroposterior ratio; VAS, visual analogue scale; TLICS, thoracolumbar injury classification and severity score; LSC, load-sharing classification.

Results of multivariable logistic regression analysis showed two significant risk factors of KR before implant removal: age and BMI $(P<0.001$, respectively). However, preoperative $\mathrm{AVH} \%(P=0.008)$ and preoperative $\mathrm{PVH} \%(P=0.008)$ were protective factors for KR (Table 2$)$.

Table 2

Results of Logistic regression analyzing risk factors of kyphosis recurrence

\begin{tabular}{|c|c|c|c|c|c|c|c|}
\hline $\begin{array}{l}\text { Implant } \\
\text { removal }\end{array}$ & Characteristics & B value & $\begin{array}{l}\text { Wals } \\
\text { value }\end{array}$ & $\begin{array}{l}P \\
\text { value }\end{array}$ & $\begin{array}{l}\text { Exp (B) } \\
\text { value }\end{array}$ & $\begin{array}{l}\text { Nagelkerke } \\
\mathrm{R}^{2} \text { value }\end{array}$ & $\begin{array}{l}\text { Total } \\
\text { percent }\end{array}$ \\
\hline \multirow[t]{5}{*}{ Before } & Age & 0.391 & 16.331 & $<0.001$ & 1.479 & 0.867 & 96.4 \\
\hline & $\mathrm{BMI}$ & 2,522 & 16.388 & $<.001$ & 12.459 & & \\
\hline & $\begin{array}{l}\text { Preoperative } \\
\text { AVH\% }\end{array}$ & -0.2038 & 6.954 & 0.008 & 0.816 & & \\
\hline & $\begin{array}{l}\text { Preoperative } \\
\text { PVH\% }\end{array}$ & -1.246 & 11.207 & 0.001 & 0.288 & & \\
\hline & Constant & 35.044 & 3.765 & 0.052 & $1.657 \times 10^{15}$ & & \\
\hline \multirow[t]{3}{*}{ After } & $\mathrm{BMI}$ & 0.811 & 33.287 & $\begin{array}{l}<.001 \\
0.01\end{array}$ & 2.250 & 0.611 & 82.1 \\
\hline & $\begin{array}{l}\text { Preoperative } \\
\text { AVH\% }\end{array}$ & -0.086 & 15.687 & $<.001$ & 0.918 & & \\
\hline & Constant & -13.380 & 18.419 & $<.001$ & $<0.001$ & & \\
\hline
\end{tabular}

The ROC curve and the area under the curve (AUC) were used to analyze the predictability of the risk factors. The results showed that age (threshold value $=49.0, A U C=0.828$ ), BMI (threshold value $=24.0$, $\mathrm{AUC}=0.846$ ) were good predictors; however, the predictabilities of preoperative $\mathrm{AVH} \%$ (threshold value $=$ 49.5, AUC $=0.348$ ) and preoperative $\mathrm{PVH} \%$ (threshold value $=85.5, \mathrm{AUC}=0.423$ ) were unsatisfactory (Table 3). 
Table 3

Results of ROC curve analyzing risk factors of kyphosis recurrence

\begin{tabular}{|lllllll|}
\hline $\begin{array}{l}\text { Implant } \\
\text { removal }\end{array}$ & Characteristics & $\begin{array}{l}\text { Area under the } \\
\text { curve }\end{array}$ & $\begin{array}{l}\text { Cut-off } \\
\text { value }\end{array}$ & Sensitivity & $\begin{array}{l}\text { 1- } \\
\text { specificity }\end{array}$ & $\begin{array}{l}\text { Youden } \\
\text { index }\end{array}$ \\
\hline Before & Age & 0.828 & 49 & 0.769 & 0.200 & 0.646 \\
& BMI & 0.846 & 24.0 & 0.846 & 0.267 & 0.579 \\
\hline & $\begin{array}{l}\text { Preoperative } \\
\text { AVH\% }\end{array}$ & 0.348 & 49.5 & 0.615 & 0.933 & -0.318 \\
\hline & $\begin{array}{l}\text { Preoperative } \\
\text { PVH\% }\end{array}$ & 0.423 & 85.5 & 0.385 & 0.667 & -0.282 \\
\hline After & BMI & 0.871 & 25.17 & 0.684 & $<0.001$ & 0.684 \\
\hline & $\begin{array}{l}\text { Preoperative } \\
\text { AVH\% }\end{array}$ & 0.317 & 61.5 & 0.3685 & 0.778 & -0.409 \\
\hline $\begin{array}{l}\text { Notice: BMI, body mass index; AVH\%, anterior vertebra height ratio; PVH\%, posterior vertebra height } \\
\text { ratio. }\end{array}$ &
\end{tabular}

\subsection{Risk factors of postoperative KR after implant removal}

The average correction loss after implant removal was $7.5 \pm 4.4^{\circ}$. Kyphosis reoccurred in $114(67.9 \%)$ patients (Fig. 2). There were significant differences between KR group and NKR group in the number of females, age, BMI $(P<0.001$, respectively), the number of cases with preoperative $\mathrm{AVH} \%$, preoperative UIVA, preoperative AVH\% $(P<0.001$, respectively), diabetes mellitus $(P=0.021)$, preoperative A/P\% $(P=$ 0.002), preoperative VAS $(P=0.008)$, preoperative $\mathrm{PVH} \%(P=0.007)$, preoperative $\mathrm{PVH} \%(P=0.010)$, preoperative $\mathrm{A} / \mathrm{P} \%(P=0.003)$, and preoperative LSC $(P=0.039)$ (Table 1$)$.

Results of multivariable logistic regression analysis showed two significant risk factors of KR after implant removal: $\mathrm{BMI}(P<0.001)$ and $\mathrm{AVH} \%(P=0.008)$. However, preoperative AVH\% was a protective factor for KR (Table 2).

The ROC cures showed that BMI (threshold value $=25.17, \mathrm{AUC}=0.871$ ) was a good predictor; however, the predictability of preoperative $\mathrm{AVH} \%$ (threshold value $=61.5, \mathrm{AUC}=0.317$ ) was unsatisfactory (Table 3).

\section{Discussion}

During daily activities, spinal posture and thoracic kyphosis influence the load distribution in vertebral body; repetitive cyclic loading will cause collapse of fractured vertebral body; these can lead to thoracolumbar kyphosis [11]. It has been reported postoperative KR may be of greater significance than postoperative vertebral body re-collapse $[12,13]$. Therefore, our study analyzed the risk factors of postoperative KR. Our study showed that correction loss progressed most rapidly within 12 months after 
surgery; correction loss progressed much slowly after implant removal. Therefore, it's necessary to separately discuss the risk factors of KR before or after implant removal.

Previous studies showed that age will primarily affect bone remodeling toward resorption; this was because vertebral body contained numerous trabecular bone [14, 15]. All these studies supported our results that age $>49$ years was a risk factor of KR before implant removal. There was a lack of studies on the correlation between $\mathrm{BMI}$ and $\mathrm{KR}$. Our study showed that $\mathrm{BMI}>24.0$ was a risk factor of $\mathrm{KR}$ before implant removal; $\mathrm{BMI}>25.17$ was a risk factor of $\mathrm{KR}$ after implant removal; these implied that $\mathrm{BMI}$ works differently at different stages after surgery. Bone healing of fractured vertebra has not been fully achieved before implant removal [16]. Therefore, a high BMI will increase the load on instruments and even lead to the deformation of implants. The fractured vertebra has healed after implant removal; therefore, the KR after implant removal may be mainly caused be the loss of UIVA correction; in this period, a higher BMI with longer action time is needed to result in space collapse, reduction of buffering capacity and degeneration of upper intervertebral discs [17]. Chung et al. [18] reported that diabetes mellitus could increase the risk of fragility fractures, which was often associated with osteoporosis. Our study showed that diabetes mellitus was not a risk factor of KR. This was because the most thoracolumbar fractures of patients with diabetes mellitus involved more than one vertebra, which was much severer than singlelevel thoracolumbar burst fractures. According to the inclusion and exclusion criteria, our study included a small number of patients with diabetes mellitus, which might influence our results.

Fractured endplates and nucleus pulposus were intruded in to fractured vertebral body during burst fracture; this could result in collapse of the cancellous framework in the vertebral body [12]. During SSPI-f, annulus fibrosus of the collapsed intervertebral disc was distracted; then the wall of fractured vertebral body was reduced by the annulus fibrosus attached to the periphery of the endplate; however, because the annulus fibrosus was not sufficiently attached to the center of the endplate, the fragmented nucleus, endplates and collapsed cancellous framework were not sufficiently reduced [12]. Similarly, our study showed that $\mathrm{AVH} \%>49.5 \%, \mathrm{PVH} \%>85.5 \%$ were protective factors of $\mathrm{KR}$ before implant removal. This was because low $\mathrm{AVH} \%$ and low $\mathrm{PVH} \%$ usually meant a severer vertebral body compression. These would lead to large bone defect created inside the fractured vertebra after reduction, which had been reported as an important reason of internal fixation failure and KR [19]. Additionally, the results in our study showed that $\mathrm{AVH} \%>61.5 \%$ was a protective factor of $\mathrm{KR}$ after implant removal, which implied that the loss of anterior vertebra height had a long-term impact on therapeutic effect. Preoperative CA, RA and VWA were not the risk factors of KR in our study. The possible explanation might be that thoracolumbar burst fractures usually involved anterior and posterior columns, both anterior and posterior walls of vertebra were fractured; therefore, compared with vertebra height, the variation of vertebra angle could not accurately the severity of thoracolumbar burst fractures [20].

The fractured endplates and nucleus pulposus were intruded into the fractured vertebral body during burst fracture, which would result in collapse of the cancellous framework in the vertebral body [21]. Similarly, Oner et al. [22] reported that even with the fracture of end plates, the upper discs were intact in most of the patients. It could be seen from the trend of parameters in our study that the loss of correction 
caused by the collapse of upper intervertebral disc of fractured vertebra was a slow process, which was not due to the adjacent disc injured by direct high-energy violence. Therefore, superior endplate fracture, the decrease of preoperative UIVA and preoperative LIVA were not the risk factors of KR.

Our results showed that preoperative VAS score could not be used to predict the risk of KR. The reason was that VAS score had strong subjectivity with many influence factors, which made its accuracy limited $[3,6]$. Pellise et al. [23] pointed out that LSC score was positively correlated with correction loss. However, our study showed that LSC score was not a risk factor of KR. The possible explanation might be that most of the previous studies discussed the curative effect of skip-level fixation without inserting additional screws into the fractured vertebra. Our study analyzed the treatment effect of SSPI-f, which could increase stiffness and reduce the failure rat of instrumentation with the insertion of two screws in the fractured vertebra; this seemed to reduce the influence of LSC score on the treatment effect [19]. TLICS was comprehensive not only in determining injury prognosis, but also in guiding treatment [24]. Our study found that TLICS was not a risk factor of KR. The reason might be that the mean TLICS was more than 4 points in our study; the fractured vertebras of patients with higher TLICS were highly unstable, which was usually treated with long-segment fixation and should be excluded from our research.

There were limitations in our study. First, it was a retrospective study that developed the detailed prediction model; however, our study was a multi-center study with strict inclusion and exclusion criteria, which was more meaningful compared with prior risk factor analysis. Second, magnetic resonance imaging (MRI) was not fully discussed in our study, which made the evaluation of soft tissue around fractured vertebra very difficult; this might lead to the omission of significant risk factors.

\section{Conclusion}

Our study proved that the effectiveness of SSPI-f in the treatment of thoracolumbar burst fractures was good; the correction loss was mainly found within 12 months after surgery. Therefore, patients should be carefully followed up within 1 year after surgery. There were significant differences in the risk factors of $\mathrm{KR}$ at different postoperative follow-up stages. Patients who have older age ( $>49$ years), higher $\mathrm{BMI}$ (> 24), lower $\mathrm{AVH} \%$ (<49.5\%) and lower PVH\% (<85.5\%) were more likely to suffer from KR before implant removal. These patients should be properly treated with conservative methods, such as waring braces and doing rehabilitation exercises, to actively prevent the occurrence of KR before implant removal. KR before implant removal is more likely to occur in patients with higher BMI (>25.17) and lower AVH\% (> $61.5 \%)$. In such patients, the removal time of internal fixation should be extended. Patients with poor physical conditions should maintain the internal fixation without removal. Among all these predictive factors, age and BMI were the most accurate factors.

\section{Abbreviations}


SSPI-f = short-segment pedicle instrumentation with screw insertion in the fractured vertebra, $\mathrm{KR}=$ the recurrence of kyphosis, $\mathrm{AVH} \%$ = anterior vertebra height ratio, $\mathrm{ROC}$ = curve: receiver operating characteristic curve, TLICS score $=$ Thoracolumbar Injury Classification and Severity score, BMD = bone mineral density, $\mathrm{CT}=$ computed tomography, $\mathrm{NKR}=$ none recurrence of kyphosis, $\mathrm{CA}=\mathrm{Cobb}$ angle, RA = regional angle, $\mathrm{VWA}=$ vertebral wedge angle, $\mathrm{AVH} \%$ = anterior vertebral height ratio, $\mathrm{AVHO}=$ anterior height of the fractured vertebra, $\mathrm{AVH} 1=$ anterior height of the upper adjacent vertebra, $\mathrm{AVH} 2=$ anterior vertebral height of the lower adjacent vertebra, $\mathrm{PVH} \%=$ posterior vertebral height ratio, $\mathrm{PVHO}=$ percentage of posterior height ratio of the fractured vertebra, $\mathrm{PVH} 1$ = posterior height of the upper adjacent vertebra, $\mathrm{PVH} 2=$ posterior height of the lower adjacent vertebra, $\mathrm{A} / \mathrm{P} \%=$ anteroposterior ratio, UIVA = upper intervertebral angle, LIVA = lower intervertebral angle, VAS = Visual Analogue Scale, LSC score $=$ Load Sharing Classification score, $\mathrm{BMI}=$ body mass index, $\mathrm{OR}=$ odds ration, $\mathrm{Cl}=$ confidence interval, $\mathrm{AUC}=$ area under the curve, $\mathrm{SE}=$ superior endplate, $\mathrm{IE}=$ inferior endplate, $\mathrm{UAV}=$ upper adjacent vertebra, $\mathrm{LAV}=$ lower adjacent vertebra.

\section{Declarations}

\section{Acknowledgements:}

The authors would like to thank Yu-Xi Liu and Miao Ou-Yang who provided data support and corrected some mistakes. This research was performed mainly at the Department of Orthopaedics of Xuanwu Hospital Capital Medical University and in the National Clinical Research Center for Geriatric Diseases.

\section{Compliance with Ethical Standards:}

Ethics Committee of the Xuanwu Hospital Capital Medical University approved this study. The approval number is Clinical study review [2018] 021. Written informed consent of each patient was obtained prior to the study. All patients included in the study provided their informed consent at enrolment on the use of patients' data for research.

\section{Conflict of interest statement:}

The authors declare that they have no conflict of interest.

\section{Authors' contributions:}

$\mathrm{XS}, \mathrm{WS}, \mathrm{HH}$ and WW were responsible for designing the search strategy, evaluating the articles and writing this article. TTZ and CK were responsible for English editing. SS was responsible for designing the protocol. SL was responsible for interpreting results.

\section{Availability of data and materials:}

Please contact author for data requests.

\section{Funding}


This study was funded by China Scholarship Council (No.201908110337), National Natural Science Foundation of China (No. 81672201, No. 81871794) and Beijing Municipal commission of Health and Family Planning (No. PXM2017 026283 000002).

\section{References}

1. Wood KB, Li W, Lebl DR, Ploumis A. Management of thoracolumbar spine fractures. SPINE J. 2014;14(1):145-64.

2. Denis $F$. The three column spine and its significance in the classification of acute thoracolumbar spinal injuries. Spine (Phila Pa 1976). 1983;8(8):817-31.

3. Chen JX, Xu DL, Sheng SR, Goswami A, Xuan J, Jin HM, Chen J, Chen Y, Zheng ZM, Chen XB, et al. Risk factors of kyphosis recurrence after implant removal in thoracolumbar burst fractures following posterior short-segment fixation. INT ORTHOP. 2016;40(6):1253-60.

4. Parker JW, Lane JR, Karaikovic EE, Gaines RW. Successful short-segment instrumentation and fusion for thoracolumbar spine fractures: a consecutive 41/2-year series. Spine (Phila Pa 1976). 2000;25(9):1157-70.

5. Formica M, Cavagnaro L, Basso M, Zanirato A, Felli L, Formica C, Di Martino A. Which patients risk segmental kyphosis after short segment thoracolumbar fracture fixation with intermediate screws? INJURY 2016, 47 Suppl 4:S29-S34.

6. Jang HD, Bang C, Lee JC, Soh JW, Choi SW, Cho HK, Shin BJ. Risk factor analysis for predicting vertebral body re-collapse after posterior instrumented fusion in thoracolumbar burst fracture. SPINE J. 2018;18(2):285-93.

7. Wang $X Y$, Dai LY, Xu HZ, Chi YL. Kyphosis recurrence after posterior short-segment fixation in thoracolumbar burst fractures. J Neurosurg Spine. 2008;8(3):246-54.

8. McCormack T, Karaikovic E, Gaines RW. The load sharing classification of spine fractures. Spine (Phila Pa 1976). 1994;19(15):1741-4.

9. Lee JY, Vaccaro AR, Lim MR, Oner FC, Hulbert RJ, Hedlund R, Fehlings MG, Arnold P, Harrop J, Bono $\mathrm{CM}$, et al. Thoracolumbar injury classification and severity score: a new paradigm for the treatment of thoracolumbar spine trauma. J ORTHOP SCI. 2005;10(6):671-5.

10. Lee MC, Solomito M, Patel A. Supine magnetic resonance imaging Cobb measurements for idiopathic scoliosis are linearly related to measurements from standing plain radiographs. Spine (Phila Pa 1976). 2013;38(11):E656-61.

11. Landham PR, Gilbert SJ, Baker-Rand HL, Pollintine P, Robson BK, Adams MA, Dolan P. Pathogenesis of Vertebral Anterior Wedge Deformity: A 2-Stage Process? Spine (Phila Pa 1976). 2015;40(12):9028.

12. Xu BS, Tang TS, Yang HL. Long-term results of thoracolumbar and lumbar burst fractures after shortsegment pedicle instrumentation, with special reference to implant failure and correction loss. ORTHOP SURG. 2009;1(2):85-93. 
13. Alanay A, Acaroglu E, Yazici M, Oznur A, Surat A. Short-segment pedicle instrumentation of thoracolumbar burst fractures: does transpedicular intracorporeal grafting prevent early failure? Spine (Phila Pa 1976). 2001;26(2):213-7.

14. Cummings SR, Melton LJ. Epidemiology and outcomes of osteoporotic fractures. LANCET. 2002;359(9319):1761-7.

15. Riggs BL, Khosla S, Melton LR. Sex steroids and the construction and conservation of the adult skeleton. ENDOCR REV. 2002;23(3):279-302.

16. Ong T, Sahota O, Tan W, Marshall L. A United Kingdom perspective on the relationship between body mass index (BMI) and bone health: a cross sectional analysis of data from the Nottingham Fracture Liaison Service. BONE 2014, 59:207-210.

17. Kim JY, Ryu DS, Paik HK, Ahn SS, Kang MS, Kim KH, Park JY, Chin DK, Kim KS, Cho YE, et al. Paraspinal muscle, facet joint, and disc problems: risk factors for adjacent segment degeneration after lumbar fusion. SPINE J. 2016;16(7):867-75.

18. Chung DJ, Choi HJ, Chung YS, Lim SK, Yang SO, Shin CS. The prevalence and risk factors of vertebral fractures in Korean patients with type 2 diabetes. J BONE MINER METAB. 2013;31(2):1618.

19. Mahar A, Kim C, Wedemeyer M, Mitsunaga L, Odell T, Johnson B, Garfin S. Short-segment fixation of lumbar burst fractures using pedicle fixation at the level of the fracture. Spine (Phila Pa 1976). 2007;32(14):1503-7.

20. Rajasekaran S, Kanna RM, Shetty AP. Management of thoracolumbar spine trauma: An overview. INDIAN J ORTHOP. 2015;49(1):72-82.

21. Reinhold M, Knop C, Beisse R, Audige L, Kandziora F, Pizanis A, Pranzl R, Gercek E, Schultheiss M, Weckbach $A$, et al. Operative treatment of 733 patients with acute thoracolumbar spinal injuries: comprehensive results from the second, prospective, Internet-based multicenter study of the Spine Study Group of the German Association of Trauma Surgery. EUR SPINE J. 2010;19(10):1657-76.

22. Oner FC, van der Rijt RR, Ramos LM, Dhert WJ, Verbout AJ. Changes in the disc space after fractures of the thoracolumbar spine. J Bone Joint Surg Br. 1998;80(5):833-9.

23. Pellise F, Barastegui D, Hernandez-Fernandez A, Barrera-Ochoa S, Bago J, Issa-Benitez D, Caceres E, Villanueva C. Viability and long-term survival of short-segment posterior fixation in thoracolumbar burst fractures. SPINE J. 2015;15(8):1796-803.

24. Whang PG, Vaccaro AR, Poelstra KA, Patel AA, Anderson DG, Albert TJ, Hilibrand AS, Harrop JS, Sharan AD, Ratliff JK, et al. The influence of fracture mechanism and morphology on the reliability and validity of two novel thoracolumbar injury classification systems. Spine (Phila Pa 1976). 2007;32(7):791-5.

\section{Figures}




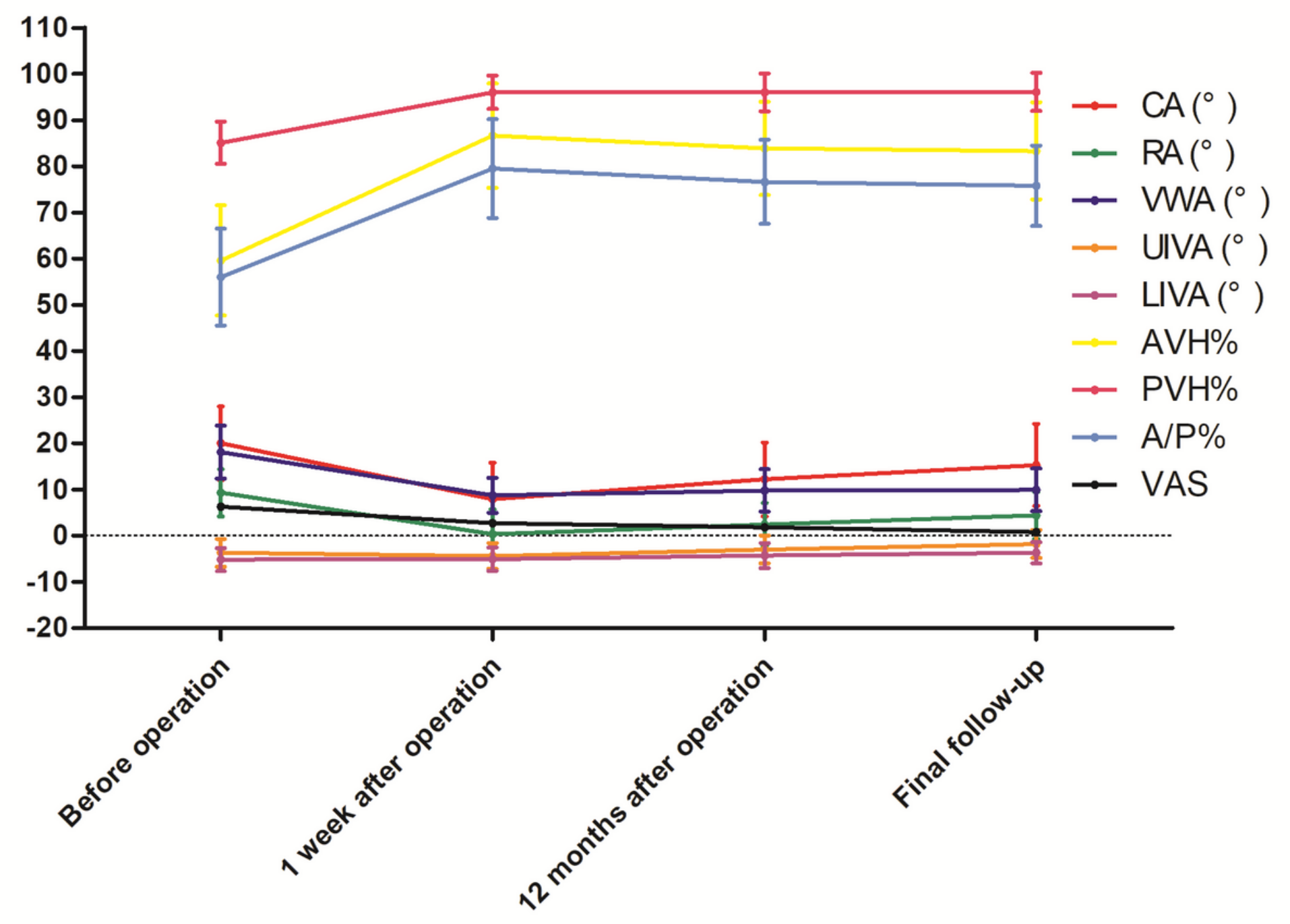

Figure 1

The trend of clinical and radiological parameters in patients with thoracolumbar burst fracture
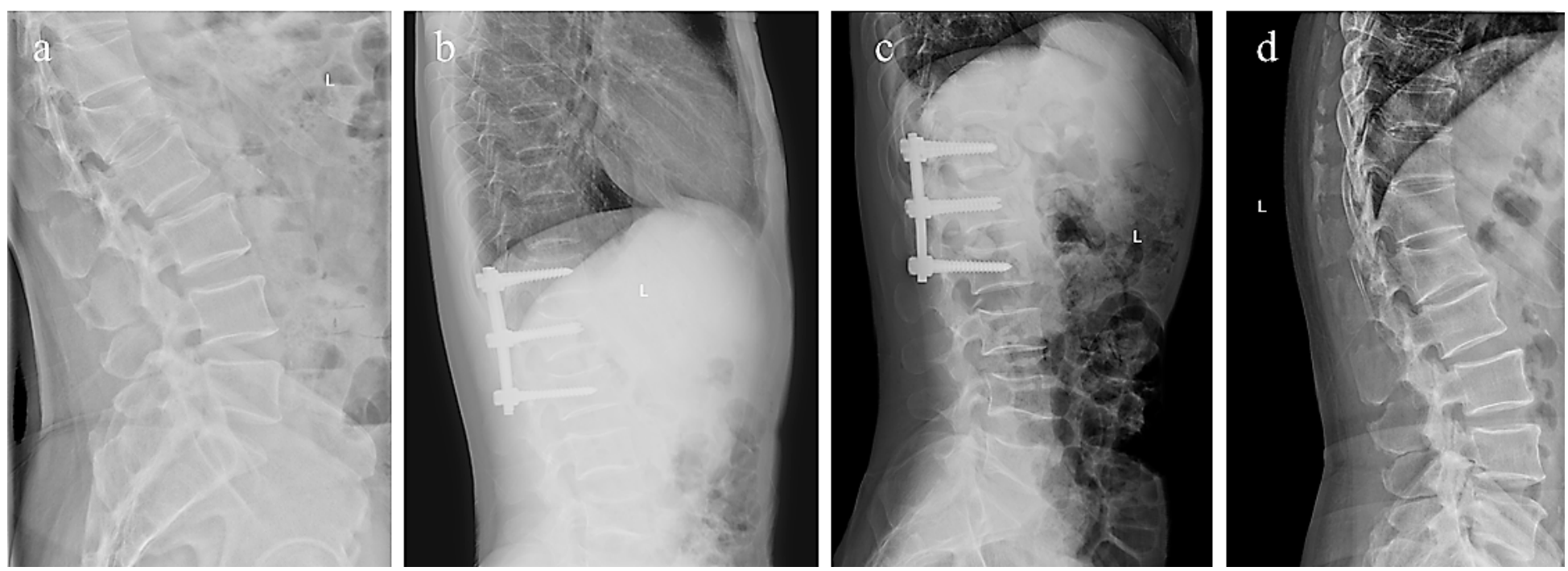
Figure 2

Radiographs of 39 years old male patient was obtained. (a) The preoperative Cobb angle (CA) of fractured segments was $27^{\circ}$. (b) one week after operation, the CA was $8^{\circ}$. (c) CA was $11^{\circ}$ before the operation. (d) CA was $21^{\circ}$ at last follow-up. 